army; but it is now generally used for the revaccinations which are so systematically carried out in the Prussian army. Its efficacy was most completely established during the late Franco-Prussian war, when small-pox was raging epidemically, and when everyone was at his wits' end to obtain lymph. The Berlin Vaccine Institution was able to meet all wants, thanks to the large stock of glycerined lymph in its possession, and so popular has the lymph treated in this way become that Dr. Müller states that applicants for lymph at the institution now generally ask to have it glycerined. Dr. Fleischman, of Vienna, has borne testimony to its value, and a considerable literature on the subject may be consulted in the pages of the medical press for the last ten years.

During the last epidemic of small-pox, in 1871-72, I was resident medical officer at the London Huspital. We were compelled, for their protection, to vaccinat $r$ the whole of the patients and employés, numbering nearly 700, and subsequently, from the old cases being succeeded by new ones, nearly as many more had to be vaccinated. Our supply of lymph was very limited; but Dr. Herman, then resident accoucheur, at my suggestion, diluted the lymph with glycerine, and so was able to meet all the wants with his stock. I communicated to The LANCET (Feb. 18, 1871) the result of the first cases, and I can add that the success there recorded was equalled in the very large number of cases subsequently vaccinated.

The proportions and method of mixing the lymph and glycerine I would advocate are those recommended by Dr. Müller, who has so large an experience on this subject. To one part of vaccine lymph is to be added two parts of pure glycerine and $t$ wo parts of distilled water. These must be thoroughly mixed by means of a glass rod in a small watchglass or capsule. The thorough admixture of the vaccine and the glycerine is most important, as the latter exercises no solvent action on the former, and when left for any length of time the two have a tendency to separate. It is highly important that the glycerine used be pure. Price's glycerine will be found a reliable preparation. Lymph so mixed with glycerine may be stored in capillary tubes or test tubes for an indefinite period; though, if it is intended to keep it long, the distilled water may be omitted from the mixture. When glycerined lymph which has been preserved in tube or bottle is required for use, it must be again thoroughly mixed by means of a glass rod. It is even stated by some that lymph so treated retains its efficacy lnnger than ordinary unmixed lymph. Of this $I$ have no experience, but for the information of those who have not heard of its employment, the following facts will show that it is at least equally effica cious, and, as I have shown, much more manageable. Dr. Wiener, of Culm, states (Med. Times and Gazette, June $3 r d, 1871$ ) that he vaccinated 1600 children with $1 \mathrm{ymph}$ mixed with glycerine in the proportion of 1 to 3 and 1 to 4 , "with the most unusual success, only five failures having, in fact, been registered." The vesicles were as fine and the course as uncomplicated as when simple lymph was employed. He also obtained equally good results in a series of vaccinations performed in February and March, 1871, with lymph collected in the previous July. The advantages which glycerined lymph presents for vaccinating large bodies of persons, the absence of waste, and the increased efficiency of the operation, can only be appreciated by those who have made trial of it.

Finsbury-square.

\section{CASE OF PHLEGMONOUS SYPHILIDES.}

BY THOMAS BARLOW, M.D., B.S.,

ASSISTANT-PHYSIOTAN TO CHARING-CROSS HOSPITAL, AND TO THE HOSPITAL FOR SIOK CHILDRYN, GREAT ORMOND-STREET.

J. W-, a boy aged ten weeks, was brought to me as an out-patient at Great Ormond-street on the 29th February, 1876. According to the mother's statement, he had been "born with a cold in his eyes and nose," and had continued to snuffle after his eyes got well; at three weeks " his skin had begun to peel off like scurf; cracks had appeared at the corners of the mouth, and within one week of that time "he had come out with a lot of boils." When brought to the hospital, there was still some desquamation in large patches about the head and face. There was nasal catarrb, and there were sores at the corners of the mouth. A few brownish maculæ on the trunk were desquamating. In addition, there were some skin lesions, which I will describe in detail. On both temporal regions, on the upper lip, on the front and back of the thorax and belly, on the thighs, and on the dorsal surface of the right big toe, were numerous boils, the average size being that of half an ordinary marblei. e., hemispherical, and about half an inch in diameter. They evidently had begun in the subcutaneous tissue, and in many of them the epidermis was quite tightly stretched and thinned out. There was scarcely any areola of redness around them, but they were very acute notwithstanding, and they contained, as I ascertained, greenish, creamy-in fact, laudable-pus. In no case was there any indurated firm mass to be felt in the skin, nor was there angthing like a "core," nor any ohvious relation to sebaceous glands. Over and above these, I must mention that on the nates there could be felt on each side a fluctuating tumour, the size of a Spanish chesnut. These were entirely subcutaneous. Subsequently they opened, and discharged pus. Secondly, on the left side, between the neck and the shoulder, was an ulcerated area two and a half inches long by balf an inch wide; and on the right side, over the supraspinous fossa, was another ulcerated area, triangular in shape-the height of the triangle about two inches, the base about one inch. Both these areas were punched out, but they were not serpiginous. There was no doubt, from the mother's account, that these areas had commenced as boils. As to the other signs: some of the glands in the groins were enlarged; nothing abnormal was detected in the chest; the liver was three fingers' breadth below the margin of the thorax, and the spleen two to three fingers' breadth below. The child had scarcely strength either to suck or cry. He lay quite torpid on his mother's knee.

In spite of the ulceration and suppuration, I put the child on grey powder, in one-grain doses three times daily. The ulcerating areas were dressed with carbolic oil at first, and subsequently with black lotion. They healed so rapidly that on the 24th of March the edges were alrnost approximated; and although I transplanted some skin-grafts on to them, there was little for the grafts to accomplish. Not more than two or three fresh boils appeared. None of these ulcerated. They discharged laudable pus, and healed up very rapidly, leaving small white cicatrices. As the skin improved, mercurial inunction into the soles was substituted for the grey powder. The child's general nutrition improved from the day the mercury was commenced. By the 1st May he was as plump and stout as any child I ever saw. The only vestiges of the skin condition were radiating cicatrices all round the mouth, slightly puckered cicatrices on the shoulders, and swall round ones on the body.

Mercurial inunction was continued till the 9 th of June. Then first the spleen ceased to be palpable; and this was taken as an indication of the syphilitic poison being in abeyance.

What was the nature of the boils that occurred in this case? They were not ordinary furuncles, for they had no inflamed areola; and, what is more essential, in no case was there any extrusion of a core of necrosed tissue. They were not the "scrofulides phlegmoneuses" of Hardy : they were infinitely more acute; they discharged laudable pus instead of thin watery stuff; and they healed more rapidly. In favour of their being gummata, it is true there was left after some of them extensive ulceration-namely, the areas on the shoulders. But there was nowhere any hard nodulax mass to be felt; there was active suppuration, not gradual breaking down, and certainly in no case was there any reabsorption.

I do not record this case as unique. Lancereaux quotes cases of subcutaneous tubercles or tumours which soon became softened and ulcerated; and Bäumler, in Ziemssen's Dictionary, refers to subcutaneous gummata precisely like the furuncles of atrophic children, with contents consisting of granular detritus, not pus.

I can only repeat that in this case the contents were laudable pus. It appears to me more correct to entitle these lesions phlegmonous syphilides or syphilitic phlegmons than subcutaneous gummata. Montague-street, W.C. 